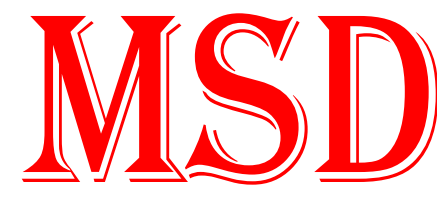

Medical Science and Discovery ISSN: 2148-6832

\title{
Clinical significance of neutrophil-to-lymphocyte ratio and platelet-to-lymphocyte ratio in liver transplantation
}

\author{
Ahmet Atlas ${ }^{1 *}$ \\ 1 Harran University School of Medicine, Dept of Anesthesiology and Reanimation, Şanlıurfa, TR \\ * Corresponding Author: Ahmet Atlas E-mail: ahmetatlas@ harran.edu.tr
}

\section{ABSTRACT}

Objective: Liver transplantation has been reported to be a predictor of patient survival in acute coronary syndrome and various malignancies, including hepatocellular carcinoma (HCC). In a previous study, it was demonstrated that high Platelet-to-Lymphocyte Ratio (PLR) values before treatment are an independent prognostic factor predicting poor survival in patients with large HCC. We aimed to investigate whether preoperative neutrophil-to-lymphocyte ratio, platelet-to-lymphocyte ratio, and thrombocyte count are prognostic factors for post transplantation mortality or graft function in patients who underwent liver transplantation in the clinic.

Material and Methods: The data of 40 patients who underwent liver transplantation in the clinic during January 2018-December 2020 were retrospectively analyzed and included in the study.

Results: The mean age of the 40 patients included in the study was $51.1 \pm 11.7$ years. Of these, 27 (67.5\%) were male, and 13 (32.5\%) were female. Living-donor liver transplantation was performed in 33 patients, whereas cadaveric liver transplantation was performed in seven patients. The mean ejection fraction (EF) was $56.7 \% \pm 3.2 \%$, and the mean model for end-stage liver disease score was $22.4 \pm 5.4$. After one year of follow-up, 10 out of 40 patients (25\%) died after orthotopic liver transplantation. The mean preoperative neutrophil count was found to be $5.7 \pm 2.4 \times 109 / 1$ in non-surviving patients and $3.1 \pm 2.05 \times 109 / 1$ in surviving patients. It was found that mortality increased in patients with high preoperative neutrophil values (NLR $>3.7, \mathrm{p}<0.001)$ and preoperative platelet count $(<79.52 \times 109 / \mathrm{L}, \mathrm{p}<0.001)$.

Conclusion: Preoperative neutrophilia, thrombocytopenia and high NLR values may predict poor prognosis in patients undergoing OLT.

Keywords: liver transplantation, neutrophil-to-lymphocyte ratio, thrombocytopenia

\section{Research Article}

Received 26-04-2021

Accepted 04-05-2021

Available Online: $15-05-2021$

Published 28-05-2021

Distributed under

Creative Commons CC-BY-NC 4.0

\section{OPEN ACCESS}

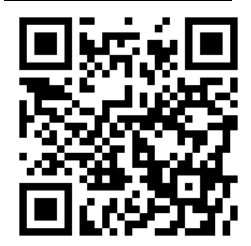

\section{INTRODUCTION}

Liver transplantation in humans was first performed in 1963. Since then, orthotopic liver transplantation (OLT) is considered the only definitive treatment in patients with endstage liver disease (1). In the USA and Western Europe, genetic disorders such as liver cirrhosis, alcoholic cirrhosis, hepatocellular carcinoma, or hemochromatosis due to viral hepatitis B or C are the main indications for OLT (2). In Turkey, liver cirrhosis due to viral hepatitis $\mathrm{B}$ (the most common cause) and due to hepatitis $\mathrm{C}$, alcoholic cirrhosis, autoimmune diseases, Wilson's disease, Budd-Chiari syndrome, and cryptogenic liver cirrhosis are the main indications for OLT (3). According to the Unified Network for Organ Sharing, the 1-year and 5-year survival rates of patients who underwent OLT are $85 \%$ and $75 \%$, respectively (4).

Neutrophil-to-lymphocyte ratio (NLR) has recently been reported as a simple and useful marker of various inflammatory changes and is calculated based on complete blood count data $(5,6)$. Increased neutrophils usually indicate that patients have a bacterial infection and that the infection is getting worse. 
Lymphocyte reduction means that immune function is poor $(7,8)$. It has been reported to be a predictor of patient survival in acute coronary syndrome and various malignancies, including hepatocellular carcinoma (HCC) (9, 10). In addition, it has been reported that high NLR value implies poor prognosis for acute-chronic liver failure after liver transplantation (11).

Platelets may play an important role in indicating posttransplant liver regeneration and dysfunction. Therefore, it has been suggested that platelet count in the acute phase of OLT is a prognostic factor for early post-transplant survival or graft function $(12,13)$.

Further, platelet-to-lymphocyte ratio (PLR) has recently been suggested to be a predictor of thrombotic and inflammatory conditions and therefore, to be an inflammation-related biomarker for tumors (14). In a previous study, it was demonstrated that high PLR values before treatment are an independent prognostic factor predicting poor survival in patients with large HCC (15). Moreover, PLR values have been shown to predict survival in ovarian, breast, and lung cancers (16-18).

OLT results were analyzed retrospectively in the organ transplant center.The usefulness of preoperative NLR, PLR values and platelet count in predicting prognosis was investigated.

\section{MATERIAL and METHODS}

Forty adult patients who underwent OLT at the organ transplant center between January 2018 and December 2020 were included in the study. After obtaining permission from the local ethics committee (Document Date and Number: 19.02.2021-12864), the patient files were retrospectively reviewed. The data of the recipients who underwent liver transplantation were accessed from the hospital information processing system, anesthesia records, intensive care nurse observations, and epicrisis records.

Patients' demographic data, cirrhosis etiology, comorbid diseases, ejection fractions (EF), Child-Pugh scores, model for end-stage liver disease (MELD) scores, and hematological parameters were analyzed. Hematological parameters such as the counts of leukocytes, neutrophils, lymphocytes, and platelets were recorded. NLR and PLR values were calculated based on the measured hematological parameters. Clinical events such as postoperative infectious complications, acute cellular rejection, or relaparotomy resulting in any surgical complications, durations of intensive care unit (ICU) and hospital stay, and mortality rates were analyzed retrospectively.

\section{Anesthesia management}

Patients who were admitted to the operating room were monitored using 12-lead electrocardiography, pulse oximetry, noninvasive blood pressure measurement, and bispectral index (BIS) monitoring. Anesthesia was induced with 3-5 $\mathrm{mg} / \mathrm{kg}$ propofol, $1-2 \mu \mathrm{g} / \mathrm{kg}$ fentanyl, and $0.6 \mathrm{mg} / \mathrm{kg}$ rocuronium. After intubation, the patients were ventilated in a volume-controlled mode with breath volume of $8 \mathrm{~mL} / \mathrm{kg}$ and respiratory rate of $10-12$ breaths per min. Anesthesia depth was monitored using a BIS monitor, (Masimo SET® Rainbow, Masimo corp., Irvine, CA) and BIS score was maintained between 40 and 60. Anesthesia was maintained with a mixture of oxygen/air containing an infusion of $2 \%$ sevoflurane, $0.1 \mathrm{mg} / \mathrm{kg} / \mathrm{h}$ rocuronium, and $0.1-0.2 \mu \mathrm{g} / \mathrm{kg} / \mathrm{min}$ remifentanil. Warming blankets were used to prevent hypothermia. Intravenous fluids were warmed before administration (Hot Line ${ }^{\circledR}$ SIMS Medical System Inc, Rocklan, MA, USA; Fluido® Pressure Chamber, TSCI, Amersfoort, Netherlands). All patients were administered electrolyte solution and $6 \%$ hydroxyethyl starch for intravascular volume replacement. Depending on the degree of hypoalbuminemia $(<3.0 \mathrm{~g} / \mathrm{dl}), 20 \%$ human albumin solution was administered. In cases when the international normalized ratio was $>1.5$ and prothrombin time was $>60 \mathrm{~s}$, the patients were administered $10 \mathrm{ml} \mathrm{kg}^{-1}$ fresh frozen plasma. Platelet suspension was given according to the platelet count $(<50000)$. Erythrocyte suspension was administered to maintain hematocrit values between $25 \%$ and $30 \%$. Noradrenaline $(0.03-0.15 \mathrm{mcg} / \mathrm{kg} / \mathrm{min})$ was initiated if the cardiac index decreased to $<2.5 \mathrm{~L} / \mathrm{min} / \mathrm{m}^{2}$ or when the mean arterial pressure (MAP) decreased to $<60 \mathrm{mmHg}$ despite adequate fluid resuscitation. Diuretics were administered when oliguria persisted despite adequate fluid resuscitation and vasopressor use. If the mean urine output was $<0.5 \mathrm{~mL} / \mathrm{kg} / \mathrm{h}$, the patients were administered furosemide $(0.5-1 \mathrm{mg} / \mathrm{kg})$. If the serum calcium level was $<8 \mathrm{mg} / \mathrm{dl}$, patients were administered $10 \%$ calcium chloride.

Hemodynamic monitoring: After induction of anesthesia, the pulse co-oximetry probe (Masimo SET® Rainbow, Masimo corp., Irvine, CA) was preferably placed on the index finger of the left hand and covered to prevent the effect of ambient light. Perfusion Index and Pleth variable index (PVI) variables were automatically measured by connecting to the Masimo monitor (Masimo corp., Irvine, CA) installed with PVI software. A 4F-thermodilution catheter (Pulsiocath ${ }^{\circledR}$; Pulsion Medical System, Munich, Germany) was placed in the left femoral artery and connected to the PICCO2 (B) system. A 3-lumen central catheter $(20 \mathrm{~cm}, 7 \mathrm{~F})$ was placed in the right internal jugular vein or subclavian vein using Seldinger technique. Body mass index and body surface areas were determined by entering the age, height, and weight information of the patients into the system. With the transpulmonary thermodilution method, cardiac output, cardiac index, systemic vascular resistance index, and volumetric preload parameters were measured by injecting 15 $\mathrm{mL}$ of cold saline (at temperature $\leqslant 8^{\circ} \mathrm{C}$ ) through the central venous line. Saline injections were performed by the same researcher, and the values were obtained by calculating the mean of three consecutive measurements. Besides these parameters, heart rate, MAP, central venous pressure, oxygen saturation, and temperature were monitored.

Surgical technique: For cadaveric liver transplantation, the entire cadaver liver was attached to the same location after the recipient's liver was removed. Hepatectomy was performed on the recipient following laparotomy with an inverted Lshaped incision. Anastomosis between the right and left hepatic veins of the cadaveric liver and the inferior vena cava was performed using the piggyback technique. Subsequently, anastomoses of the portal vein, hepatic artery, and bile duct were performed. Cadaveric liver grafts were prepared using histidine-tryptophan-ketoglutarate solution (Dr Franz Köhler Chemie GmbH, Bensheim, Germany). For living-donor liver 
transplantation, the right lobe of the donor liver was attached to the recipient. Hepatectomy was performed in the recipient after the completion of laparotomy with an inverted L-shaped incision. Anastomosis between the right hepatic vein of the donor liver and the inferior vena cava was performed using the piggyback technique, followed by anastosmoses of the portal vein, hepatic artery, and bile duct.

Statistical analysis: Statistical analyses of the data were performed using IBM SPSS 24.0 (IBM Corp. Released 2015. IBM SPSS Statistics for Windows, Version 24.0. Armonk, NY: IBM Corp.). Whether the data showed normal distribution was examined by Shapiro-Wilk test. MannWhitney $U$ test was used to compare the non-normal distributed data of two independent groups. Chi-square test was used to investigate the relationship between two categorical variables. $\mathrm{P}$ value of $<0.05$ was considered statistically significant.

\section{RESULTS}

The mean age of the 40 patients included in the study was $51.1 \pm 11.7$ years, of whom $27(67.5 \%)$ were male, and 13 $(32.5 \%)$ were female. Living-donor liver transplantation and cadaveric liver transplantation were performed in 33 and 7 patients, respectively. The demographic characteristics of these patients are presented in Table 1. The most common indication for OLT was liver cirrhosis due to hepatitis B virus (HBV) $(57.5 \%)$, followed by cryptogenic liver cirrhosis (30\%), liver cirrhosis due to hepatitis $\mathrm{C}$ virus (HCV) $(7.5 \%)$, alcoholic liver cirrhosis $(2.5 \%)$, and Wilson's disease $(2.5 \%)$. The mean EF value and MELD score were $56.7 \% \pm 3.2 \%$ and $22.4 \pm 5.4$, respectively. In addition, the mean duration of hospital stay was $14.8 \pm 6.6$ days, whereas that of ICU stay was $6.1 \pm 2.8$ days. Comorbid diseases of the patients were hypertension in 5 patients, diabetes mellitus in 5 patients, coronary artery disease in 4 patients, chronic obstructive pulmonary disease in 1 patient, and myxoma in 1 patient (Table 1).

In the study, 11 patients underwent relaparotomy after OLT 10 due to postoperative bleeding and 1 due to portal vein thrombosis. The patient who developed portal vein thrombosis underwent a second liver transplantation. The most common postoperative complication was bleeding. Biliary stenosis was detected in two patients, and endoscopic biliary drainage was applied to these patients.

After one year of follow-up, 10 out of 40 patients died after OLT $(25 \%)$. The mean age of these patients was $52.7 \pm 11.4$ years. The mean MELD score of non-surviving patients was found to be $28.5 \pm 4.1$. Mortality was higher in patients with higher MELD scores $(\mathrm{p}=0.011)$. The mean preoperative neutrophil count was found to be $5.7 \pm 2.4 \times 10^{9} / 1$ in nonsurviving patients and $3.1 \pm 2.05 \times 10^{9} / 1$ in surviving patients. It was found that mortality increased in patients with higher preoperative neutrophil counts $(\mathrm{p}=0.012)$. The mean preoperative NLR was $6.8 \pm 2.5$ in non-surviving patients and $2.5 \pm 1$ in the surviving patients. The cut-off value of the preoperative NLR was $>3.7$ with sensitivity and specificity of $100.00 \%$ and $92.00 \%$ respectively (Figure 1). The mortality rate was higher in patients with preoperative NLR of $>3.7$ (p $=0.025$ ). Mean preoperative platelet count was found to be $62.2 \pm 18.3 \times 10^{9} / 1$ in non-surviving patients, and
$119.3 \pm 39.9 \times 10^{9} / 1$ in surviving patients. Preoperative thrombocyte cut-off value was $<79.52 \times 10^{9} / 1$ with sensitivity $88.89 \%$, and specificity $96.00 \%$ (Figure 2). Preoperative thrombocytopenia was also found to be a sign of poor prognosis in patients who underwent OLT $(\mathrm{p}=0.047)$. Mean preoperative PLR was found to be $78.3 \pm 26.6$ in nonsurviving patients and $109.2 \pm 40.9$ in surviving patients. Decreased PLR was more common in non-surviving patients $(\mathrm{p}=0.062)$, although the difference was not significant. The mean duration of surgery in non-surviving patients was $12.3 \pm$ $1.1 \mathrm{~h}$. It was found that prolonged operation time was associated with increased mortality $(\mathrm{p}=0.043)$ (Table 2).

Mean EF in non-surviving patients was $57.2 \% \pm 2.6 \%$, and it was found to have no effect on mortality $(p=0.616)$. Mean preoperative hemoglobin values of non-surviving patients and surviving patients were $11.4 \pm 1.5 \mathrm{~g} / \mathrm{dl}$ and $10.7 \pm 1.9 \mathrm{~g} / \mathrm{dl}$, respectively, whereas the respective mean preoperative leukocyte counts in non-surviving patients and surviving patients were found to be $7.1 \pm 2.3 \times 10^{9} / 1$ and $5.9 \pm 4.8 \times$ $10^{9} / 1$. Preoperative hemoglobin level and leukocyte count had no effect on mortality $(\mathrm{p}=0.335, \mathrm{p}=0.472$, respectively). Preoperative lymphocyte count was $0.9 \pm 0.3 \times 109 / 1$ in nonsurviving patients and $1.2 \pm 0.6 \times 10^{9} / 1$ in surviving patients. Preoperative lymphocyte count had no effect on mortality ( $\mathrm{p}$ $=0.077)$.

Among non-surviving patients, 7 were diagnosed with HBV, 2 with $\mathrm{HCV}$, and 1 with cryptogenic liver cirrhosis. Among the causes of death were multiple organ failure due to cell rejection in 5 patients, sepsis due to infection in 3 patients, portal vein thrombosis in 1 patient, and postoperative bleeding in 1 patient. No significant difference was found between the groups of non-surviving patients and survived after OLT in terms of their duration of ICU stay and hospital stay $(\mathrm{p}=0.321, \mathrm{p}=0.063$, respectively). Five of the nonsurviving patients were re-operated for postoperative bleeding and one patient due to portal vein thrombosis. Mortality was found to be high in patients who were re-operated $(\mathrm{p}=0.016)$. It was observed that the source of the grafts, living donor or cadaver, had no effect on mortality ( $p=0.888)$ (Table 3).

Table 1. Demographic data of the patients

\begin{tabular}{|lc|}
\hline Age $($ Mean \pm SD) & Patient $(\mathbf{n}=\mathbf{4 0})$ \\
\hline Sex n $(\%)$ & $51.7 \pm 11.7$ \\
Male & \\
Female & $27(67.5)$ \\
Comorbid diseases n (\%) & $13(32.5)$ \\
DM & \\
HT & $5(12.5)$ \\
CAD & $5(12.5)$ \\
COPD & $4(10)$ \\
Myxoma & $1(2.5)$ \\
MELD (Mean \pm SD) & $1(2.5)$ \\
Etiology n $(\%)$ & $22.4 \pm 5.4$ \\
HBV & \\
Cryptogenic liver cirrhosis & $23(57.5)$ \\
HCV & $12(30)$ \\
Alcoholic cirrhosis & $3(7.5)$ \\
Wilson's disease & $1(2.5)$ \\
EF (Mean \pm SD) & $1(2.5)$ \\
\hline
\end{tabular}

CAD: coronary artery disease, COPD: chronic obstructive pulmonary disorder, DM: diabetes mellitus, EF: ejection fraction HBV: hepatitis B virus, HCV: hepatitis C virus, HT: hypertension, M: Mean, MELD: model for endstage liver disease, SD: Standard deviation 
Table 2. Comparison of clinical data of surviving and non-surviving patients

\begin{tabular}{|c|c|c|c|c|}
\hline & $\begin{array}{c}\text { Surviving } \\
(\mathbf{n}=\mathbf{3 0}) \\
\text { Mean } \pm \text { SD }\end{array}$ & $\begin{array}{c}\text { Non-surviving } \\
(\mathbf{n}=\mathbf{1 0}) \\
\text { Mean } \pm \text { SD }\end{array}$ & OR $[95 \% \mathrm{CI}]$ & $\mathrm{p}$ \\
\hline Age (years) & $50.6 \pm 12.1 /$ & $52.7 \pm 11.4$ & 1.02 [0.95 -1.09] & 0.642 \\
\hline EF $(\%)$ & $56.6 \pm 3.45$ & $57.2 \pm 2.6$ & $1.07[0.83-1.36]$ & 0.616 \\
\hline MELD & $19.8 \pm 3.2$ & $28.5 \pm 4.1$ & $1.93[1.16-3.21]$ & $0.011^{*}$ \\
\hline Preoperative Hb (g/dL) & $10.7 \pm 1.9$ & $11.4 \pm 1.5$ & $1.23[0.81-1.88]$ & 0.335 \\
\hline Preoperative leukocyte $\left(\times 10^{9} / \mathbf{l}\right)$ & $5.9 \pm 4.8$ & $7.1 \pm 2.3$ & $1.06[0.9-1.26]$ & 0.472 \\
\hline Preoperative neutrophil $\left(\times 10^{9} / \mathrm{I}\right)$ & $3.1 \pm 2.05$ & $5.7 \pm 2.4$ & $1.62[1.11-2.37]$ & $0.012 *$ \\
\hline Preoperative lymphocyte $\left(\times 10^{9} / 1\right)$ & $1.2 \pm 0.6$ & $0.9 \pm 0.3$ & $0.17[0.02-1.21]$ & 0.077 \\
\hline NLR & $2.5 \pm 1$ & $6.8 \pm 2.5$ & $10.56[1.34-83.1]$ & $0.025 *$ \\
\hline Preoperative platelet $\left(\times 10^{9} / \mathrm{l}\right)$ & $119.3 \pm 39.9$ & $62.2 \pm 18.3$ & $0.8[0.64-1]$ & $0.047 *$ \\
\hline PLR & $109.2 \pm 40.9$ & $78.3 \pm 26.6$ & $0.97[0.94-1]$ & 0.062 \\
\hline Duration of operation (h) & $11 \pm 1.8$ & $12.3 \pm 1.1$ & $1.9[1.02-3.53]$ & $0.043 *$ \\
\hline
\end{tabular}

EF: ejection fraction, Hb: hemoglobin, M: mean, Max: maximum, MELD: model for end-stage liver disease, Min: minimum, NLR: neutrophil-tolymphocyte ratio, PLR: platelet-to-lymphocyte ratio, SD: standard deviation. *Significant at 0.05 level; Binary logistic regression.

Table 3. Relationship of mortality with categorical variables

\begin{tabular}{|c|c|c|c|c|}
\hline & & $\begin{array}{c}\text { Surviving } \\
(\mathbf{n}=\mathbf{3 0}) \\
n(\%)\end{array}$ & $\begin{array}{c}\text { Non-surviving } \\
(\mathbf{n}=\mathbf{1 0}) \\
n(\%)\end{array}$ & $\mathrm{p}$ \\
\hline Sex & $\begin{array}{l}\text { Male } \\
\text { Female }\end{array}$ & $\begin{array}{c}22(73.4) \\
8(26.6)\end{array}$ & $\begin{array}{l}5(50) \\
5(50)\end{array}$ & 0.220 \\
\hline Diagnosis & $\begin{array}{l}\text { HBV } \\
\text { Cryptogenic LC } \\
\text { HCV } \\
\text { Alcoholic LC } \\
\text { Wilson's disease }\end{array}$ & $\begin{aligned} 16 & (53.4) \\
11 & (36.7) \\
1 & (3.3) \\
1 & (3.3) \\
1 & (3.3)\end{aligned}$ & $\begin{array}{c}7(70) \\
1(10) \\
2(20) \\
0 \\
0\end{array}$ & 0.106 \\
\hline Relaparotomy & $\begin{array}{l}\text { Yes } \\
\text { No }\end{array}$ & $\begin{array}{c}5(16.7) \\
25(83.3)\end{array}$ & $\begin{array}{l}6(60) \\
4(40)\end{array}$ & $0.016 *$ \\
\hline Donor & $\begin{array}{l}\text { Living } \\
\text { Cadaver }\end{array}$ & $\begin{array}{c}25(83.3) \\
5(16.7) \\
\end{array}$ & $\begin{array}{l}8(80) \\
2(20) \\
\end{array}$ & 0.888 \\
\hline
\end{tabular}

HBV: hepatitis B virus, HCV: hepatitis C virus, LC: liver cirrhosis, *Significant at 0.05 level; Chi-square test.

Receiver operating characteristic curve analysis of neutrophil-tolymphocyte ratio

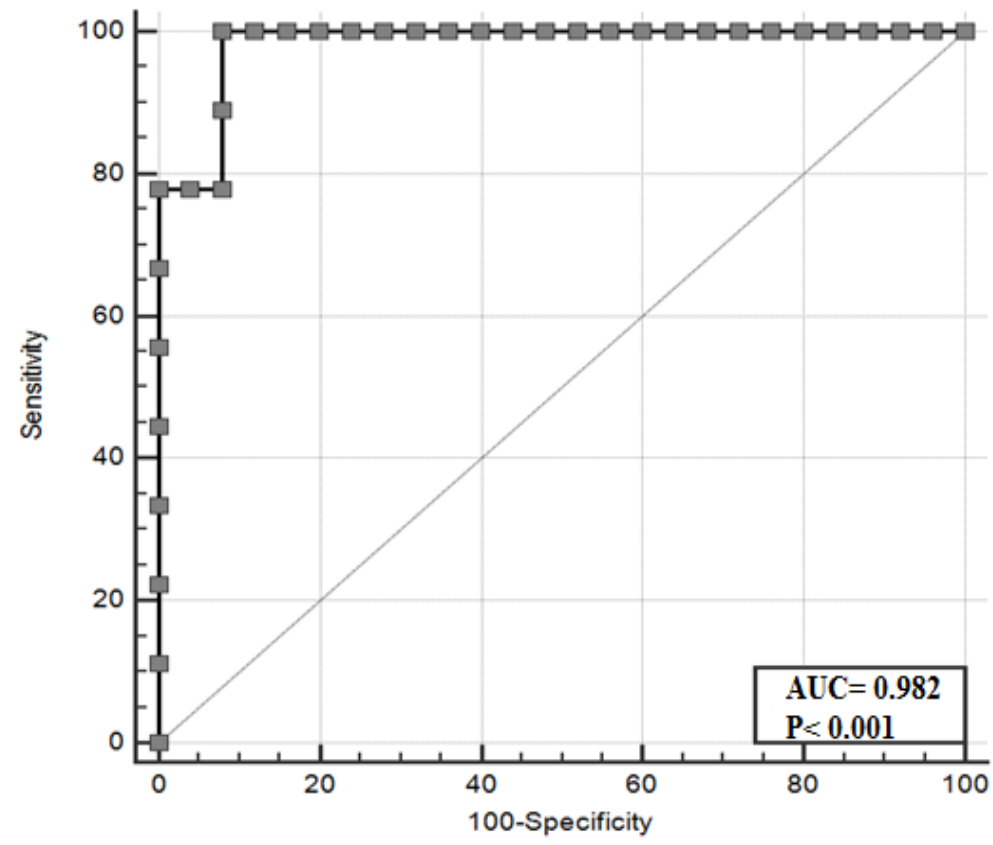

Figure 1: For the preoperative NLR value, it was found that AUC $=0.98 \pm 0.02$ and $\mathrm{p}=0.001$. The recommended optimal cut-off point was $>3.7$. For values greater than this, sensitivity for mortality was $100 \%(95 \% \mathrm{CI}=66.4-100)$, and specificity was $92 \%(95 \% \mathrm{CI}=74 \%-99 \%)$. Sensitivity and specificity were found to be significant since these did not fall within the $50 \%$ CI. AUC: area under curve, CI: confidence interval, NLR: neutrophil-to-lymphocyte ratio 
Receiver operating characteristic curve analysis of preoperative platelet count

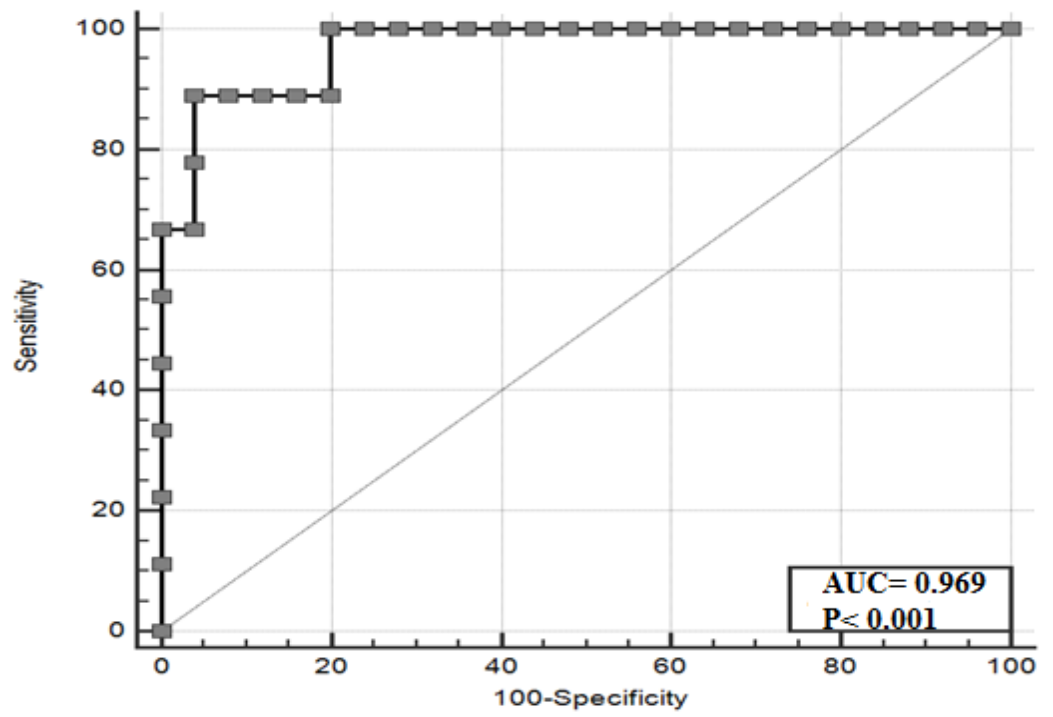

Figure 2: For the preoperative platelet value, it was found that $\mathrm{AUC}=0.97 \pm 0.03$ and $\mathrm{p}=0.001$. The recommended optimal cut-off point was $\leq 79.52$. For values less than or equal to this, sensitivity for mortality was $88.89 \%$ ( $95 \%$ CI $=$ 51.8-99.7), and specificity was $96 \%$ (95\% CI $=79.6 \%-99.9 \%)$. Sensitivity and specificity were found to be significant since these did not fall within the $50 \%$ CI. AUC: area under curve, CI: confidence interval

\section{DISCUSSION}

This retrospective single-center study investigated one-year graft and patient survival after OLT. Overall, $75 \%$ of the patients survived it was one year. It was found that preoperative neutrophilia, thrombocytopenia, and high NLR value correlated with poor prognosis and were successful in predicting mortality in patients who underwent OLT.

Ischemia-reperfusion injury (IRI) is a major cause of morbidity and mortality due to graft rejection after liver transplantation. It is responsible for $10 \%$ of early transplant failures $(19,20)$. During IRI, an intense inflammatory process occurs in the liver. Although this hepatic inflammation begins in the ischemic period, it mainly occurs during the reperfusion phase. Neutrophils are considered to be the main factor involved in the inflammatory process after reperfusion $(21,22)$. Studies have shown that elimination of increased neutrophils or inhibition of their functions leads to a decrease in liver damage and inflammation (23-25). In the study, the neutrophil count was $5.7 \pm 2.4 \times 10^{9} / 1$ in non-surviving patients, and $3.1 \pm 2.05 \times 10^{9} / 1$ in surviving patients. Consistent with the literature, a higher mortality rate was found in those patients with preoperative neutrophil elevation $(\mathrm{p}=0.012)$ in the study.

Lymphopenia has been shown to be a prognostic marker for posttraumatic survival (26). Another study reported that lymphopenia is reported to be a simple prognostic factor for overall survival in patients with metastatic breast cancer, nonHodgkin's lymphoma, and advanced sarcoma (27). Fernández-Ruiz et al. (28) found that pre OLT lymphocyte count can predict the incidence of infection during two years after OLT.
In the study, preoperative lymphocyte count was found to be $0.9 \pm 0.3 \times 10^{9} / 1$ in non-surviving patients and $1.2 \pm 0.6 \times 10^{9} / 1$ in surviving patients. In the study, a decrease in preoperative lymphocyte count was found to have no effect on mortality.

NLR has been proposed as a new biomarker for systemic inflammation, in which both neutrophil and lymphocyte counts are taken into account (29). Many studies have shown that NLR has a prognostic value in various conditions including sepsis, cardiovascular diseases, and malignant tumors (30-32). Normal NLR values range between 0.78 and 3.53 and are a simple parameter to easily assess a patient's inflammatory status (33). Further, NLR was reported to be an important parameter in predicting recipient prognosis after OLT (34). In the study, the preoperative NLR value was found as $6.8 \pm 2.5$ in non-surviving patients and $2.5 \pm 1$ in surviving patients. For the preoperative NLR value, the area under curve (AUC) according to receiver operating characteristic (ROC) curve analysis was found to be $0.98 \pm$ 0.02 , and the corresponding p-value was 0.001. The recommended optimal cut-off point was $>3.7$. For patients with values higher than the optimal cut-off points, sensitivity and specificity were $100 \%$ [95\% confidence interval $(\mathrm{CI})=$ 66.4-100] and 92\% (95\% CI $=74 \%-99 \%)$, respectively. Mortality was found to be higher in patients who underwent OLT with a preoperative NLR value of $>3.7$.

It has been reported that there is a relationship between low platelet count and poor prognosis after OLT (35). Nobuoka et al. (36) reported that thrombocytopenia is the result of sinusoidal endothelial cell damage and decreased thrombopoietin production. 
Han et al. (37) found that preoperative platelet count is an important host factor affecting HCC recurrence after livingdonor liver transplantation. Platelets have an important role in liver regeneration and dysfunction after transplantation. Therefore, the platelet count in the acute phase of OLT is reportedly a good prognostic factor for survival or graft function after OLT (12). In the study, preoperative thrombocyte count was $62.2 \pm 18.3 \times 10^{9} / 1$ in non-surviving patients, and $119.3 \pm 39.9 \times 10^{9} / 1$ in surviving patients. For the preoperative platelet value, AUC was $0.97 \pm 0.03(p=0.001)$ and the recommended optimal cut-off point was $\leqslant$ $79.52 \times 10^{9} / 1$. For patients with values less than or equal to the optimal value, the sensitivity and specificity for determining mortality were $88.89 \%$ (95\% CI $=51.8-99.7)$ and $96 \%(95 \%$ $\mathrm{CI}=79.6 \%-99.9 \%)$. Increased mortality was found in patients with preoperative platelet counts $\leqslant 79.52 \times 10^{9} / 1$.

Recent studies have focused on the correlation of NLR and PLR with tumors. In colorectal cancer and cervical cancer, higher degrees of lymph node metastases have been reported in patients with high PLR $(12,38,39)$. Xue et al. (40), observed that high PLR predicts poor prognosis in patients with $\mathrm{HCC}$ receiving trans arterial chemoembolization. In the study, the PLR values in non-surviving and surviving patients were found to $78.3 \pm 26.6$ and $109.2 \pm 40.9$, respectively. PLR level was found to be higher in surviving patients. However, this difference was not significant in terms of mortality $(\mathrm{p}=$ 0.062).

MELD score is used as a scoring tool to assign priority levels to patients on liver transplant waiting lists. It can predict 3month mortality risk with $83 \%-87 \%$ accuracy. The mortality of patients in waiting lists is directly proportional to the MELD score; a MELD score of $<9$ is associated with $2 \%$ mortality, whereas that of $\geqslant 40$ is associated with a mortality of $\leqslant 71 \%$ (41). Panchal et al. (42), retrospectively analyzed the data of 33,398 patients who underwent the transplant and found that $74 \%$ of the recipients had a MELD score of $<30$, $18 \%$ had MELD score $30-39$, and $8 \%$ had $\geqslant 40$. Consequently, they showed that overall patient survival was inversely proportional to increasing MELD score. In the study, mean MELD score was 22.4 \pm 5.4 respective mean MELD scores of non-surviving and surviving patients were $28.5 \pm 4.1$ and $19.8 \pm 3.2$. The findings were consistent with the literature, and the mortality rate was higher in patients with high MELD scores.

Olthoff et al. (43), examined the results of 385 cases of adultto-adult living-donor liver transplant recipients in nine healthcare centers and found the mean duration of recipient operations to be $8.5 \pm 2.1 \mathrm{~h}$. A previous study in the country evaluated liver transplantation surgery data of 81 patients with end-stage liver disease, 16 of whom received cadaveric transplants, whereas 65 received living-donor transplants; mean operation time was reported as $7.15 \pm 1.4 \mathrm{~h}$ (44). The mean operation time in the study was found to be $11 \pm 1.8$ hours, with the mean operation time of $12.3 \pm 1.1 \mathrm{~h}$ in nonsurviving patients. The results show that prolonged duration of the operation is associated with mortality.

The limitations of this study include its retrospective study design and low sample size since the center is a newly founded one.

\section{CONCLUSIONS}

Preoperative neutrophilia, thrombocytopenia and high NLR values may indicate poor prognosis in patients undergoing OLT. With these simple indices, high-risk patients can be identified and preventive measures can be taken.

Author Contributions: AA: Data collection, Formal analysis, Methodology, Project administration, Statistical Analyzes, AA: Article writing and revisions

Financial \& competing interest's disclosure: The authors have no relevant affiliations or financial involvement with any organization or entity with a financial interest in or financial conflict with the subject matter or materials discussed in the manuscript. This includes employment, consultancies, honoraria, stock ownership or options, expert testimony, grants or patents received or pending, or royalties.

Ethical approval: The study was conducted according to the guidelines of the Declaration of Helsinki and approved by Ethical Committee for Clinical Research of the Harran University (Document Date and Number: 19.02.2021-12864). All authors declare originality of research.

Informed consent: Informed consent was obtained from all parturient individuals and their spouses included in the study.

Conflict of interest: The authors declared no potential conflicts of interest with respect to the research, authorship, and/or publication of this article. This research did not receive and specific grant from funding agencies in the public, commercial, or not-for-profit sectors.

\section{REFERENCES}

1. Starzl T, Marchioro T, von Kaulla K, Hermann G, Brittain R, Waddell W. homotransplantation of the liver in humans. surg. gynecol. obstet. 117: 659. PubMed| CAS| Web of Science® Times Cited. 1963;522.

2. Udompap P, Kim D, Kim WR. Current and future burden of chronic nonmalignant liver disease. Clinical Gastroenterology and Hepatology. 2015;13(12):2031-41

3. Turkey Organ Transplant Foundation. 2020. Available from: https://www.tonv.org.tr/karaciger-nakli/.

4. Roberts MS, Angus DC, Bryce CL, Valenta Z, Weissfeld L. Survival after liver transplantation in the United States: a disease-specific analysis of the UNOS database. Liver transplantation. 2004;10(7):886 97.

5. Bhutta H, Agha R, Wong J, Tang TY, Wilson YG, Walsh SR Neutrophil-lymphocyte ratio predicts medium-term survival following elective major vascular surgery: a cross-sectional study. Vascular and endovascular surgery. 2011;45(3):227-31.

6. Duffy BK, Gurm HS, Rajagopal V, Gupta R, Ellis SG, Bhatt DL Usefulness of an elevated neutrophil to lymphocyte ratio in predicting long-term mortality after percutaneous coronary intervention. The American journal of cardiology. 2006;97(7):993-6

7. Celikbilek M, Dogan S, Ozbakır O, Zararsız G, Kücük H, Gürsoy S, et al. Neutrophil-lymphocyte ratio as a predictor of disease severity in ulcerative colitis. Journal of clinical laboratory analysis. 2013;27(1):726.

8. Huang H, Wan X, Bai Y, Bian J, Xiong J, Xu Y, et al. Preoperative neutrophil-lymphocyte and platelet-lymphocyte ratios as independent predictors of $\mathrm{T}$ stages in hilar cholangiocarcinoma. Cancer management and research. 2019;11:5157. 
9. Walsh S, Cook E, Goulder F, Justin T, Keeling N. Neutrophillymphocyte ratio as a prognostic factor in colorectal cancer. Journal of surgical oncology. 2005;91(3):181-4.

10. Gomez D, Farid S, Malik H, Young A, Toogood G, Lodge J, et al Preoperative neutrophil-to-lymphocyte ratio as a prognostic predictor after curative resection for hepatocellular carcinoma. World journal of surgery. 2008;32(8):1757-62.

11. Lin B-Y, Zhou L, Geng L, Zheng Z-Y, Jia J-J, Zhang J, et al. High neutrophil-lymphocyte ratio indicates poor prognosis for acute-onchronic liver failure after liver transplantation. World Journal of Gastroenterology: WJG. 2015;21(11):3317.

12. Lesurtel M, Raptis DA, Melloul E, Schlegel A, Oberkofler C, El-Badry $\mathrm{AM}$, et al. Low platelet counts after liver transplantation predict early posttransplant survival: the 60-5 criterion. Liver Transplantation. 2014;20(2):147-55.

13. Li L, Wang H, Yang J, Jiang L, Yang J, Wang W, et al. Immediate postoperative low platelet counts after living donor liver transplantation predict early allograft dysfunction. Medicine. 2015;94(34).

14. Templeton AJ, Ace O, McNamara MG, Al-Mubarak M, Vera-Badillo FE, Hermanns T, et al. Prognostic role of platelet to lymphocyte ratio in solid tumors: a systematic review and meta-analysis. Cancer Epidemiology and Prevention Biomarkers. 2014;23(7):1204-12.

15. Wang Y, Attar BM, Fuentes HE, Jaiswal P, Tafur AJ. Evaluation of the prognostic value of platelet to lymphocyte ratio in patients with hepatocellular carcinoma. Journal of gastrointestinal oncology. 2017;8(6):1065.

16. Raungkaewmanee S, Tangjitgamol S, Manusirivithaya S, Srijaipracharoen S, Thavaramara T. Platelet to lymphocyte ratio as a prognostic factor for epithelial ovarian cancer. Journal of gynecologic oncology. 2012;23(4):265

17. Krenn-Pilko S, Langsenlehner U, Thurner E, Stojakovic T, Pichler M, Gerger A, et al. The elevated preoperative platelet-to-lymphocyte ratio predicts poor prognosis in breast cancer patients. British journal of cancer. 2014;110(10):2524-30.

18. Liu H, Wu Y, Wang Z, Yao Y, Chen F, Zhang H, et al. Pretreatment platelet-to-lymphocyte ratio (PLR) as a predictor of response to firstline platinum-based chemotherapy and prognosis for patients with nonsmall cell lung cancer. Journal of thoracic disease. 2013;5(6):783.

19. Mendes-Braz M, Elias-Miró M, Jiménez-Castro M, Casillas-Ramírez A, Ramalho F, Peralta C. The current state of knowledge of hepatic ischemia-reperfusion injury based on its study in experimental models. Journal of Biomedicine and Biotechnology. 2012;2012.

20. Papadopoulos D, Siempis T, Theodorakou E, Tsoulfas G. Hepatic ischemia and reperfusion injury and trauma: current concepts. Archives of Trauma Research. 2013;2(2):63.

21. Honda M, Takeichi T, Asonuma K, Tanaka K, Kusunoki M, Inomata Y. Intravital imaging of neutrophil recruitment in hepatic ischemiareperfusion injury in mice. Transplantation. 2013;95(4):551-8.

22. Vedder NB, Fouty BW, Winn RK, Harlan JM, Rice CL. Role of neutrophils in generalized reperfusion injury associated with resuscitation from shock. Surgery. 1989;106(3):509-16.

23. Tsujii S, Okabayashi T, Shiga M, Takezaki Y, Sugimoto T, Kobayashi $\mathrm{M}$, et al. The effect of the neutrophil elastase inhibitor sivelestat on early injury after liver resection. World journal of surgery. 2012;36(5):1122-7.

24. Uchida Y, Freitas MCS, Zhao D, Busuttil RW, Kupiec-Weglinski JW. The protective function of neutrophil elastase inhibitor in liver ischemia and reperfusion injury. Transplantation. 2010;89(9):1050.
25. Xue F, Wang G, Pang Z, Liu C, Liang T. Protective Effect of Glutathione Against Liver Warm Ischemia-Reperfusion Injury in Rats is Associated with Regulation of P-Selectin and Neutrophil Infiltration. The Anatomical Record: Advances in Integrative Anatomy and Evolutionary Biology: Advances in Integrative Anatomy and Evolutionary Biology. 2008;291(8):1016-22

26. Heffernan DS, Monaghan SF, Thakkar RK, Machan JT, Cioffi WG, Ayala A. Failure to normalize lymphopenia following trauma is associated with increased mortality, independent of the leukocytosis pattern. Critical Care. 2012;16(1):1-10.

27. Ray-Coquard I, Cropet C, Van Glabbeke M, Sebban C, Le Cesne A, Judson I, et al. Lymphopenia as a prognostic factor for overall survival in advanced carcinomas, sarcomas, and lymphomas. Cancer research. 2009;69(13):5383-91

28. Fernández-Ruiz M, López-Medrano F, Romo EM, Allende LM, Meneu JC, Fundora-Suárez Y, et al. Pretransplant lymphocyte count predicts the incidence of infection during the first two years after liver transplantation. Liver transplantation. 2009;15(10):1209-16.

29. Atlas A, Duran E, Pehlivan B, Pehlivan VF, Erol MK, Altay N. The Effect of Increased Neutrophil Lymphocyte Ratio on Mortality in Patients Operated on Due to Hip Fracture. Cureus. 2020;12(1).

30. Russell CD, Parajuli A, Gale HJ, Bulteel NS, Schuetz P, de Jager CP, et al. The utility of peripheral blood leucocyte ratios as biomarkers in infectious diseases: a systematic review and meta-analysis. Journal of Infection. 2019;78(5):339-48.

31. Huguet E, Maccallini G, Pardini P, Hidalgo M, Obregon S, Botto F, et al. Reference Values for Neutrophil to Lymphocyte Ratio (NLR), a Biomarker of Cardiovascular Risk, According to Age and Sex in a Latin American Population. Current problems in cardiology. 2019:100422

32. Mei Z, Shi L, Wang B, Yang J, Xiao Z, Du P, et al. Prognostic role of pretreatment blood neutrophil-to-lymphocyte ratio in advanced cancer survivors: a systematic review and meta-analysis of 66 cohort studies. Cancer treatment reviews. 2017;58:1-13.

33. Forget P, Khalifa C, Defour J-P, Latinne D, Van Pel M-C, De Kock M. What is the normal value of the neutrophil-to-lymphocyte ratio? BMC research notes. 2017;10(1):1-4.

34. Harimoto N, Shirabe K, Nakagawara H, Toshima T, Yamashita Y-i, Ikegami T, et al. Prognostic factors affecting survival at recurrence of hepatocellular carcinoma after living-donor liver transplantation: with special reference to neutrophil/lymphocyte ratio. Transplantation 2013;96(11):1008-12

35. Chatzipetrou MA, Tsaroucha AK, Weppler D, Pappas PA, Kenyon NS, Nery JR, et al. Thrombocytopenia after liver transplantation. Transplantation. 1999;67(5):702-6.

36. Nobuoka Y, Wada H, Mizuno S, Kishiwada M, Usui M, Sakurai H, et al. Prolonged thrombocytopenia after living donor liver transplantation is a strong prognostic predictor irrespective of history of splenectomy: the significance of ADAMTS13 and graft function. International journal of hematology. 2014;99(4):418-28

37. Han S, Lee S, Yang JD, Leise MD, Ahn JH, Kim S, et al. Risk of posttransplant hepatocellular carcinoma recurrence is greater in recipients with higher platelet counts in living donor liver transplantation. Liver Transplantation. 2018;24(1):44-55.

38. Kwon H-C, Kim SH, Oh SY, Lee S, Lee JH, Choi H-J, et al. Clinical significance of preoperative neutrophil-lymphocyte versus plateletlymphocyte ratio in patients with operable colorectal cancer. Biomarkers. 2012;17(3):216-22. 
39. Dan W, Ming W, Feng F-z, Huang H-f, Yang J-x, Keng S, et al Pretreatment neutrophil-to-lymphocyte and platelet-to-lymphocyte ratios do not predict survival in patients with cervical cancer treated with neoadjuvant chemotherapy and radical hysterectomy. Chinese medical journal. 2013;126(8):1464-8.

40. Xue T-C, Jia Q-A, Ge N-L, Zhang B-H, Wang Y-H, Ren Z-G, et al The platelet-to-lymphocyte ratio predicts poor survival in patients with huge hepatocellular carcinoma that received transarterial chemoembolization. Tumor Biology. 2015;36(8):6045-51.

41. Wiesner R, Edwards E, Freeman R, Harper A, Kim R, Kamath P, et al. Model for end-stage liver disease (MELD) and allocation of donor livers. Gastroenterology. 2003;124(1):91-6.
42. Panchal HJ, Durinka JB, Patterson J, Karipineni F, Ashburn S, Siskind E, et al. Survival outcomes in liver transplant recipients with Model for End-stage Liver Disease scores of 40 or higher: a decade-long experience. HPB. 2015;17(12):1074-84.

43. Olthoff KM, Merion RM, Ghobrial RM, Abecassis MM, Fair JH, Fisher RA, et al. Outcomes of 385 adult-to-adult living donor liver transplant recipients: a report from the A2ALL Consortium. Annals of surgery. 2005;242(3):314.

44. Yaprak O, Dayangac M, Balcı D, Duran C, Uraz S, Ayanoğlu Ö, et al. Karaciğer nakli sonuçları üzerinde kan transfüzyonlarının etkisi ve transfüzyon gereksinimini etkileyen faktörler. 2008. 